\title{
Vibration Characteristic Analysis of Axial Fan Shell Based on ANSYS Workbench
}

\author{
Lichun Gu \\ College of Mechanical and Electrical Engineering \\ Yunnan Agricultural University \\ Kunming, China \\ E-mail:liuwenmin365@126.com \\ Lichang Chen \\ College of Mechanical and Electrical Engineering \\ Yunnan Agricultural University \\ Kunming, China \\ E-mail:liuwenmin365@ 126.com
}

\author{
Zhiqun Guo \\ College of Mechanical and Electrical Engineering \\ Yunnan Agricultural University \\ Kunming, China \\ E-mail:liuwenmin365@126.com
}

\begin{abstract}
Axial fans with the advantages of its simple structure, large amount of wind, widely used in agriculture that respect, but agricultural cross flow fan in the size range of big, prone to resonance problems. In this paper, to a certain type of agricultural pipeline fixed shaft flow fan shell as the research object, using the ANSYS Workbench for the modal analysis. Analysis showed that: When the external excitation frequency is within the range of $102 \mathrm{~Hz} 161 \mathrm{~Hz}$ and $354 \mathrm{~Hz} 356 \mathrm{~Hz}$, the large deformation displacement of the shell is in the direction of the $\mathrm{X}$ and $\mathrm{Y}$ direction; The analysis results provided theoretical basis for the optimum design of the shell of the axial fan and the selection of the drive motor.
\end{abstract}

Keywords-Axial Fan; ANSYS Workbench; Modal Analysis;Harmonic Response Analysis; Vibration

\section{INTRODUCTION}

Axial flow fan is a fan of airflow and wind vane in the same direction due to its simple structure and large volume in agricultural ventilation obtained widely application[1-3]. Agricultural cross flow fan in a larger size of range, the fan is in operation, blade and gas group resulting from the interaction of noise and vibration, the design needs to avoid the natural frequency of the fan and prevents vibration volume caused by wind leaf sweep chamber, the damaged parts and high noise fault[4-5]. This paper uses ANSYS Workbench for the modal analysis and harmonic response analysis to a fixed pipeline type axial flow fan shell.

\section{SHELL MODEL}

The research object is a fixed pipeline type shaft flow fan shell and the inner diameter of the pipe is $825 \mathrm{~mm}$, pipe wall thickness is $4 \mathrm{~mm}$, fixed flange width of $20 \mathrm{~mm}$, pipeline length of $600 \mathrm{~mm}$, the establishment the parametric model of the research object with Creo based on the size of the fan shell.

After the completion of the model, the model file is converted into the.IGS file of the.PRT format of the Creo format, and is imported into the Workbench ANSYS, as shown in Figure 1. Although Workbench ANSYS can
import.PRT file format, but due to the software version of the restrictions, not necessarily to be successful import. IGS is a general format for CAD file, which is mainly used for file conversion of different 3D software system. It can effectively avoid the trouble that the model can't successfully import[6].

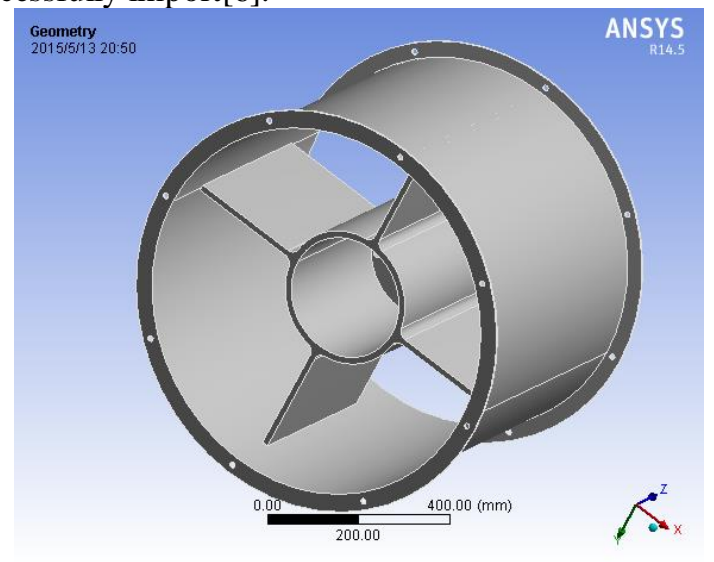

Figure 1. Fan shell model

\section{MATERIAL DEFINITION AND MESHING}

ANSYS Workbench provides not only widely used in engineering materials and related parameters, but also allows users to create their own material type in the material library. If necessary, define a name in the Workbench for QSTE420T material, the elastic modulus of 200GPa, Poisson's ratio of 0.3 , a density of $7.85 \times 103 \mathrm{~kg}$ $/ \mathrm{m} 3$. And the impeller model defined for this material.

The extent of the grid structure and density directly affects the accuracy of the calculation, and the mesh coarseness increases will increase the computing time and storage space on your computer. Ideal for the analysis of the situation no longer change with the coarseness of the mesh change, but cannot make up for the error fine mesh inaccurate assumptions and inputs caused. 
In ANSYS Workbench, the division method of the grid mainly contains automatic meshing, tetrahedral mesh, hexahedral dominant meshing, sweep method[7]. This paper adopts automatic mesh grid method, and adding a number of parameters to control on the impeller mesh, finite element mesh model as shown in Figure 2, a total of 444655 nodes, 245426 units.

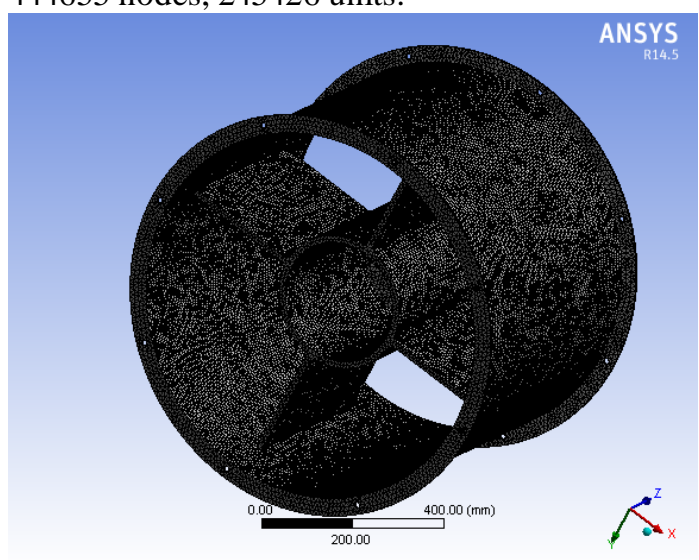

Figure 2. Finite element mesh

ANSYS Workbench provides a powerful method of grid division and also provides grid statistics and quality evaluation methods, such as unit quality, Jacobian ratio, parallel deviation, deviation etc. Skewness is one of the main methods for grid quality checking. There are two algorithms, namely Skewness Normalized and Equiangular Skewness Equilateral-Volume-Based. The value is between 0 and 1 , and the 0 represents the best, and the 1 represents the worst[7]. As shown in Figure 3, in the Skewness assessment diagram, about $86 \%$ of the unit distribution between $0-0.38,90 \%$ of the unit distribution between $0-0.5$, indicating that the grid is good, accord with the analysis requirements.

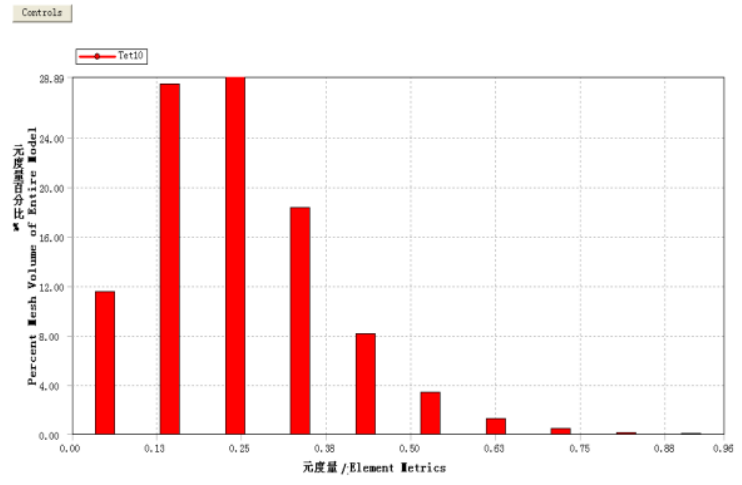

Figure 3. The assessment of mesh quality

\section{MODAL ANALYSIS}

\section{A. Modal Analysis Principles}

The modal analysis is a common method for studying the dynamic characteristics, vibration analysis and dynamic optimization of mechanical structure. Mode is the inherent characteristic of mechanical structure, each structure has multiple modes, each mode has a corresponding vibration frequency w I and modal shape \& Oslash; I, they can calculated by the following equation[8]:

$$
\left([K]-\omega_{i}^{2}[M]\right)\left\{\phi_{i}\right\}=0
$$

Where, $[\mathrm{K}]$ is the stiffness matrix, mass matrix $[\mathrm{M}]$, are assumed to be constant.

The mode is determined by the geometry of the structure, material properties and constraints. In this paper, the load and restraint of the static analysis are used, and the modal analysis of the impeller is carried out, and the stress mode equations are as follows:

$$
\left([K+S]-\omega_{i}^{2}[M]\right)\left\{\phi_{i}\right\}=0
$$

With the do not consider prestressed modal analysis compared to prestressed modal analysis considered static analysis results, considering the elements and nodes of the prestressed, closer to the working condition of the impeller, makes the modal analysis results more accurate and and the modal shapes are reflected more real[8].

\section{B. Applied Load}

Pipeline fixed axial fan casing at work are fixed through the flange, the paper will be more practically fix sixteen screw holes on the housing flange with a fixed constraint.

\section{Modal Analysis Results}

With the increasing order, the error of the modal analysis results will be larger. Based on need, using Block lanczos method to extract only the first six impeller modal analysis, the results are shown in Table 1 below:

TABLE I. ANALYSIS OF THE RESULTS OF THE FIRST EIGHT MODES

\begin{tabular}{|l|c|l|}
\hline Mode & Frequency[Hz] & Max \\
\hline 1 & 100.41 & 3.3118 \\
\hline 2 & 100.41 & 3.3117 \\
\hline 3 & 165.06 & 4.3001 \\
\hline 4 & 345.17 & 9.6833 \\
\hline 5 & 352.1 & 11.937 \\
\hline 6 & 352.18 & 11.941 \\
\hline 7 & 357.36 & 8.993 \\
\hline 8 & 387.24 & 2.9 \\
\hline
\end{tabular}

Figure 4 and Figure 5 are shell's one modal and second mode shapes cloud, and their vibration frequency is relatively similar, it should be a double root vibration equation, this happens in modal analysis symmetrical structure is normal. Their shapes are also similar, except that there is a phase difference resonance. In both modal, the maximum displacement occurs at the center position of the shell. ANSYS Workbench is a default on the mass matrix normalized modal, the numerical sizes shown in the figure are not real displacement sizes, just a point displacement ratio [9]. 


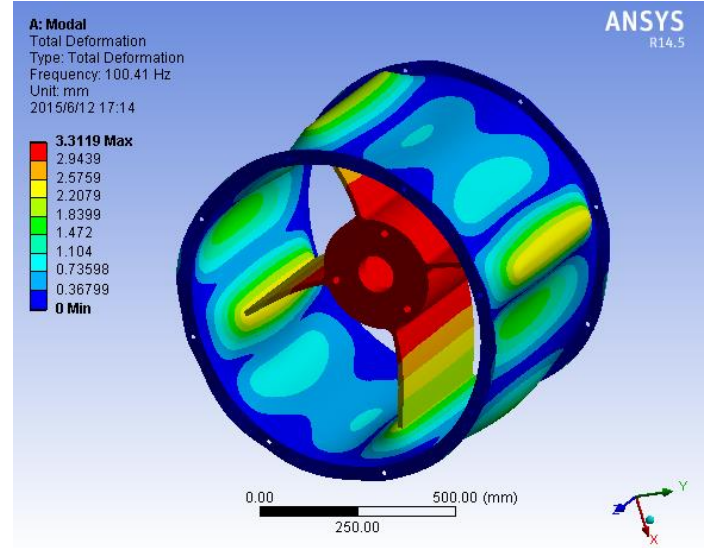

Figure 4. The first mode cloud

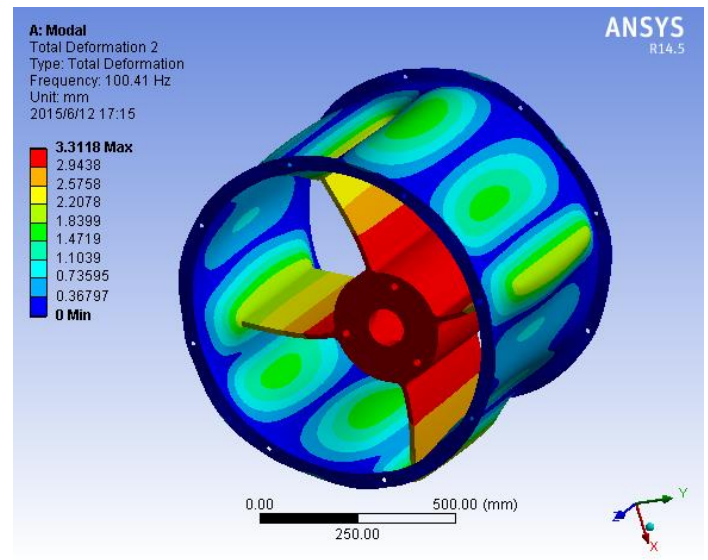

Figure 5. The Second Mode Cloud

Figure 6 shows the third mode cloud of the shell, the maximum displacement occurs at the center of the housing, smaller housing wall deformation.

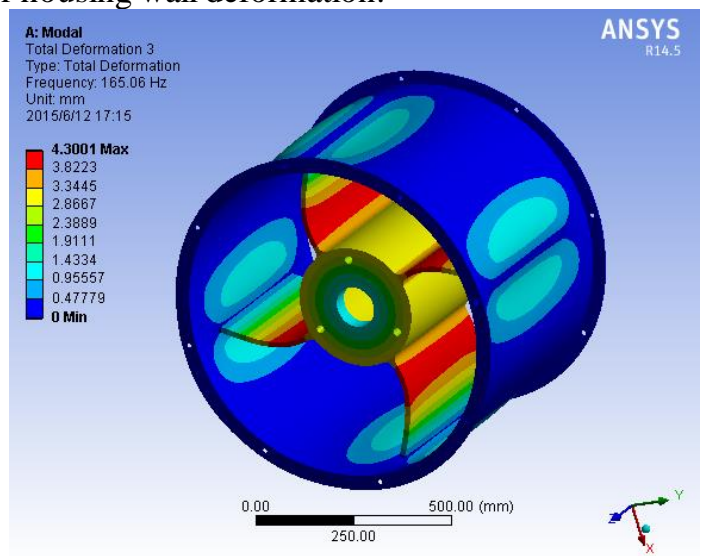

Figure 6. The Third Mode Cloud

Figure 7 shows the fourth mode cloud of the shell, smaller housing wall deformation, the maximum displacement occurs at the center of the housing.

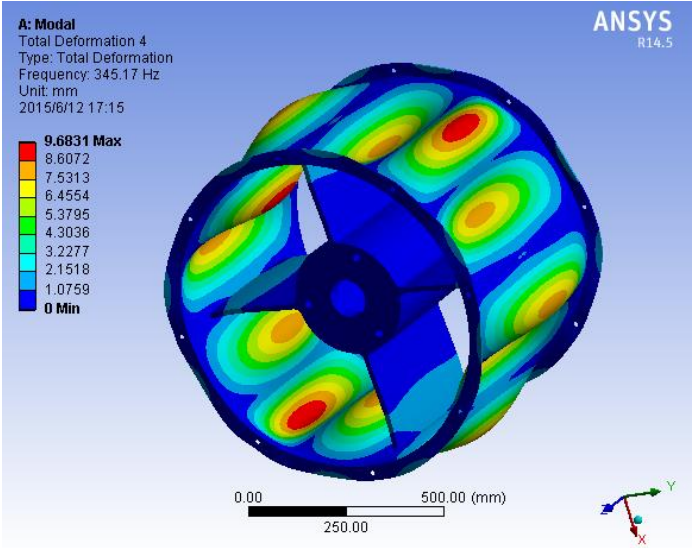

Figure 7. The fourth mode cloud

Figure 8 and Figure 9 are shell's fifth modal and sixth modal shapes cloud, they have the same vibration frequency, it should be a double root vibration equation.

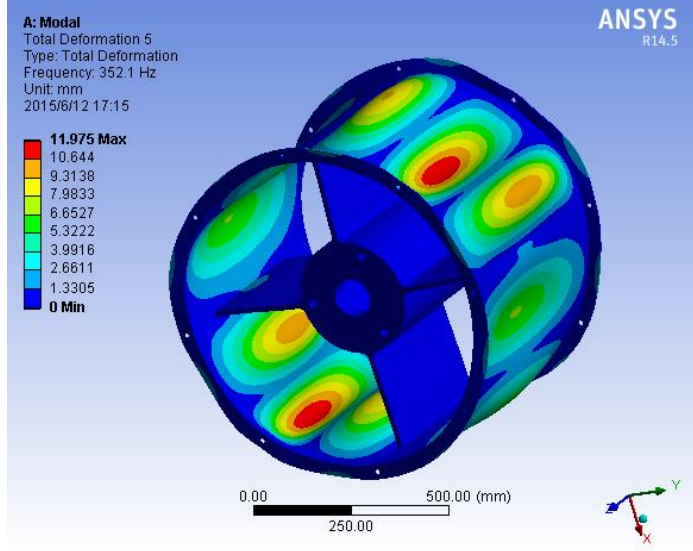

Figure 8. The Fifth Mode Cloud

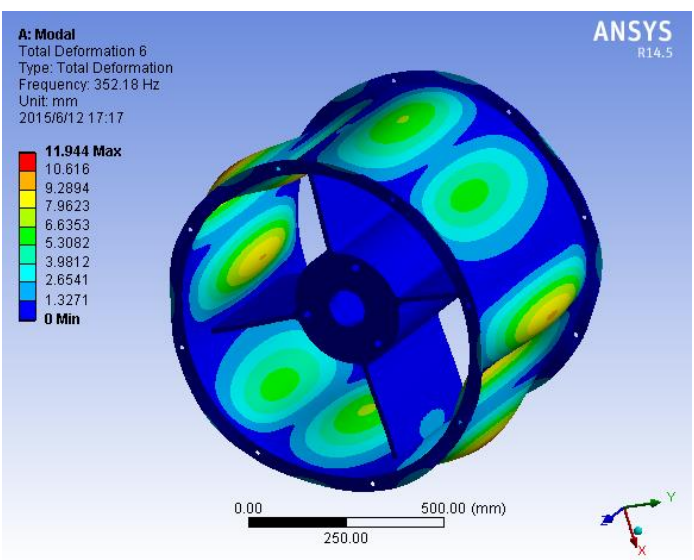

Figure 9. The Sixth Mode Cloud

Figure 10 is the case of the seventh modal shape of the shell, the middle part of the deformation is small, deformation occurs mainly in the outer wall of the shell, and is concave and white, and the entire outer wall to one side of the shift. 


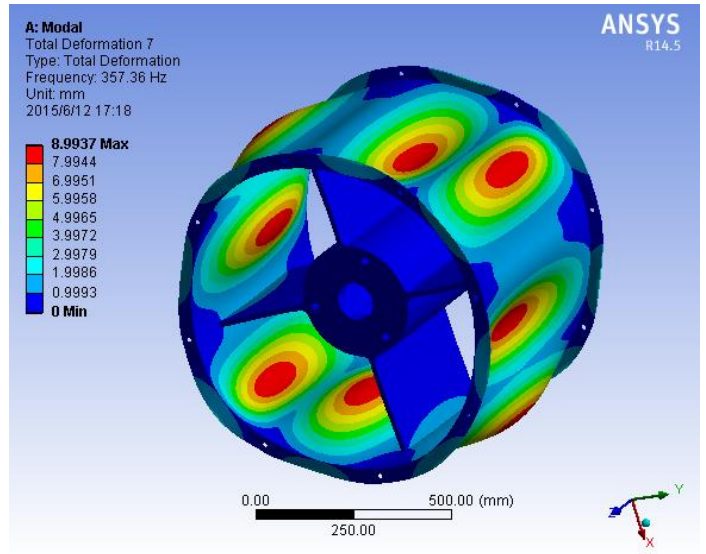

Figure 10. The seventh mode cloud

Figure 11 is the case of the eighth modal shape of the shell, the entire shell has a large displacement, where the largest displacement occurs in the middle part of the.

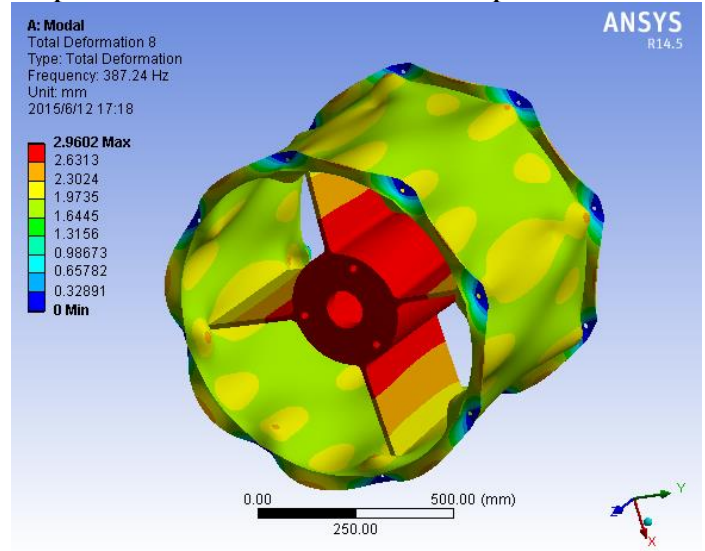

Figure 11. The eighth mode cloud

\section{HARMONIC RESPONSE ANALYSIS}

In the modal type of cloud and ANSYS Workbench default is a mass matrix normalized modal, as shown in the figure, the numerical size, and not the real displacement size, just point displacement ratio. In order to get the vibration characteristics of the shell more accurately, the harmonic response of the shell is analyzed, and the relationship between the frequency and the displacement of the shell is obtained.

\section{A. Harmonic response analysis principle}

The harmonic response is analyzed by scanning in the frequency domain, and then the structure is analyzed under different frequency and amplitude load, so the resonance is detected. The general mechanics equation for the object is $[10-11]$ :

$$
[\mathrm{M}][\mathrm{x}\}+[\mathrm{C}]\{\hat{\mathrm{x}}]+[\mathrm{K}][\mathrm{x}\}=\{\mathrm{F}(\mathrm{t})\}
$$

Where, $[\mathrm{M}]$ is the mass matrix; $\{\mathbb{X}\}$ is the acceleration vector; [C] damping matrix; $\{\mathrm{X}\}$ velocity vector; $[\mathrm{K}]$ stiffness matrix; $\{\mathrm{x}\}$ displacement vector.

In harmonic response analysis, the force $\{\mathrm{F}(\mathrm{t})\}$ is a harmonic load $\left\{\mathrm{F}_{0} \cos (\omega t)\right\}$, the harmonic load into the formula (4):

$$
[\mathrm{M}][\ddot{\mathrm{X}}]+[\mathrm{C}]\{\hat{\mathrm{x}}\}+[\mathrm{K}][\mathrm{x}\}=\left\{\mathrm{F}_{0} \cos (\omega \mathrm{t})\right\}
$$

\section{B. Harmonic response analysis setup}

By the shell's modal analysis shows that the first eight order mode of vibration frequency scope of $100.41 \mathrm{~Hz} 387.24 \mathrm{~Hz}$. Due to the high frequencies of resonance structure with smaller, so within the range, shell occurred serious vibration of the possibility of a larger [9]. Based on the modal analysis results will be harmonic response analysis to solve the frequency segment is set to $100 \mathrm{~Hz} 300 \mathrm{~Hz}$, in order to get more accurate frequency and displacement relationship curve, frequency scanning interval selection is $2 \mathrm{~Hz}$. To solve the frequency range of 150 steps, this paper calculates the harmonic response analysis.

\section{Slving and post-processing}

The relationship between the frequency and displacement of at any node of the model is obtained by solving after, axial flow fan of stand-alone installed in the middle position of the shell, the middle position of the shell vibration will direct influence on the vibration of the shaft of the motor, thereby affecting the vibration of the fan blade, the middle position of the vibration of axial flow fan is one of the greatest impact. For accurate analysis of the intermediate housing part of the vibration characteristics of selected at the middle part of the node memory processing, obtained the frequency of the node and the nodes along the $\mathrm{X}$ direction displacement relationship curve, frequency and node along the $\mathrm{Y}$ direction displacement relationship curve, frequency and node along the $\mathrm{Z}$ direction displacement relationship curve.

Position of the node in the $\mathrm{X}$ direction displacement mainly affects motor blade in the $\mathrm{X}$ direction, Figure 12 for frequency and the frame along the $\mathrm{X}$ direction displacement relationship curve, the curve by multi extremum, which in the $102 \mathrm{~Hz} 161 \mathrm{~Hz}, 354 \mathrm{~Hz} 356 \mathrm{~Hz}$ range will appear larger relative displacement and the maximum displacement value for $7.97 \mathrm{~mm}$.

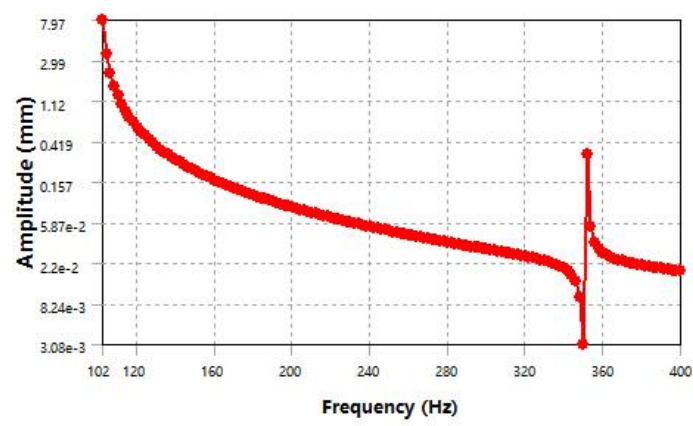

Figure 12. The relationship curve between frequency and Displacement of nodes along the $\mathrm{X}$ direction

Due to the $\mathrm{X}$ axis and the $\mathrm{Y}$ axis are located within the blade plane, second only vibration phase difference of 90 degrees, so frequency nodes along the $\mathrm{X}$ direction displacement relationship curves and frequency - node along the $\mathrm{Y}$ direction displacement relationship curve is basically the same.

Position of the node in the $\mathrm{Z}$ direction displacement mainly affects motor blade in the $\mathrm{Z}$ direction, Figure 13 for frequency and the frame along the $\mathrm{Z}$ direction displacement relationship curve, the curve is more extreme, which in the $356 \mathrm{~Hz} 390 \mathrm{~Hz}$ range will appear larger 
relative displacement, but the maximum displacement value for $1.44 \mathrm{e}-2 \mathrm{~mm}$.

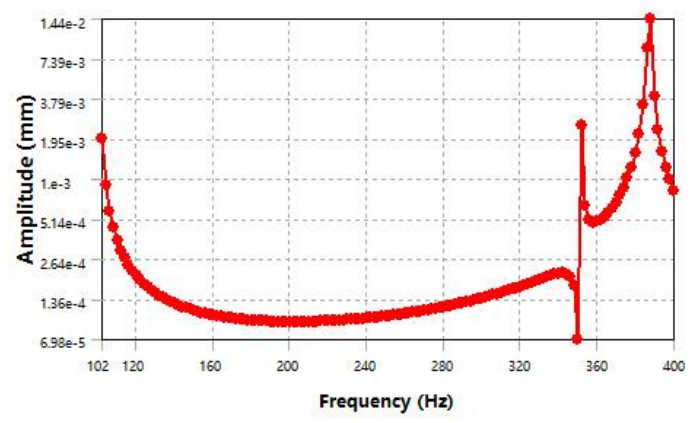

Figure 13. The relationship curve between frequency and Displacement of nodes along the $\mathrm{Z}$ direction

Vibration of the middle position of the shell nodes along the $\mathrm{X}$ direction and the $\mathrm{Y}$ direction will directly affect the wind turbine blade in the shell space position, if the amplitude of vibration is too large will lead directly to the sweep chamber and other hazards; middle position of the shell nodes along the $\mathrm{Z}$ direction of vibration will directly affect the blade in the axial direction of the shell, affect the normal work of the fan is not; from the harmonic response analysis results can be seen in the middle position of the shell along the $\mathrm{X}$ direction and the $\mathrm{Y}$ direction of displacement is larger, along the $\mathrm{Z}$ direction of the displacement is small, in the selection of fan drive motor, should avoid to choose the excitation frequency in $102 \mathrm{~Hz} \sim 161 \mathrm{~Hz}, 354 \mathrm{~Hz} \sim 356 \mathrm{~Hz}$ within the scope of motor.

\section{CONCLUSIONS}

(1) The displacement of the middle part of the fan housing is large, and the number of the reinforcement plates can be increased and the stability of the intermediate part is increased.
(2) When the external excitation frequencies are within $102 \mathrm{~Hz} \sim 161 \mathrm{~Hz}, 354 \mathrm{~Hz} 356 \mathrm{~Hz}$ range, the shell part along the $\mathrm{X}$ direction and the $\mathrm{Y}$ direction will appear larger displacement, so the choice of fan drive motor should avoid the frequency range.

\section{REFERENCES}

[1] Tingwei Zeng. Axial fan design research and development of CAD software [D]. Zhejiang University, 2006.

[2] Mingang Zhen. Fan of [D]. Tianjin University performance simulation of axial tunnel, 2006.

[3] Liangyu Ma,Wei Duan,Bing Wang. The general mathematical performance model $[\mathrm{J}]$. Thermal power engineering of the axial flow fan, 2001,02:195-198+226-227.

[4] Haiying Wu. Numerical study of the influence of design elements on the performance of axial fans [D]. Inner Mongolia University of Technology, 2014

[5] GuoLiang Qin, Hengxin Liu, Liang Zhu. Agricultural low-pressure axial flow fan development of automatic testing system [J]. General machinery, 2003,07:57-60.

[6] [6]Yu Wang, Yonglong Lin,Libo Zhou. Model data conversion between Pro / E and Ansys software to study [J]. lifting transport machinery, 2013 (12): 108-109.

[7] Xinlong Ding,Guilong Ling. ANSYS Workbench 14.5 finite element analysis case Xiangjie [M]. Tsinghua University press, 2014:87-92.

[8] Jicheng Li,Lin Guo,Tianhui Zhang. Based on fluid solid coupling combine cross flow fan impeller dynamic characteristics analysis [J]. Agricultural Mechanization Research, 2015,09:234-240.

[9] Yanping Li. Finite element analysis and optimization of the centrifugal fan impeller [D]. Northwest Agriculture and Forestry University, 2012.23-24.

[10] Shufeng Huang, Yuncai Zhao. Analysis of column mode and harmonic response of vertical powder mill [J]. mining research and development, 2012,06:94-97.

[11] Tao Liu,Weihui Wang,Fei Lu. Workbench based box arm modal and harmonic response analysis [J]. manufacturing automation, 2015,04:80-82+97. 